\title{
9. Elevers förståelse av lärares skriftliga återkoppling i ämnet engelska
}

Karina Pålsson Gröndahl

Det är viktigt att elever lär sig att uttrycka sig skriftligt på ett främmande språk som engelska. Engelska är ett språk som används i internationella sammanhang och i högre utbildning vid flera högskolor och universitet i Sverige. Av detta skäl är det viktigt att lärare i ämnet engelska undervisar i skrivande och använder verktyg som både utvecklar elevers skrivande och motiverar dem till att fortsätta skriva. Ett sådant verktyg är skriftlig återkoppling. Skriftlig återkoppling har huvudsakligen undersökts utifrån ett lärarperspektiv där frågor som vad lärare ger återkoppling på, hur ger lärare återkoppling och varför lärare ger återkoppling stått i fokus. Däremot är det få studier som belyser hur elever förstår och använder den skriftliga återkoppling som lärare ger. Det är detta det här kapitlet handlar om.

\section{Skriftlig återkoppling ur ett elevperspektiv}

Idén att undersöka återkoppling ur ett elevperspektiv föddes i klassrummet och den utgick från ett intresse för skrivundervisning i ämnet engelska samt för hur elevers skrivande kan utvecklas och hur deras motivation för skrivande kan stärkas.

Eftersom återkoppling som ges till elever rörande deras prestationer syftar till att tydliggöra för eleverna var de befinner sig i lärandeprocessen, vart de är på väg och hur de bäst kan ta sig till målet knyter återkopplingsprocessen ihop både lärande och motivation för att lära. Följaktligen blir återkopplingsprocessen intressant och relevant att undersöka för just lärare. Särskilt intressant

Hur du refererar till det här kapitlet:

Pålsson Gröndahl, K. (202I). Elevers förståelse av lärares skriftliga återkoppling $\mathrm{i}$ ämnet engelska. I Bardel, C. et al. (Red.). Forskarskolan FRAM — lärare forskar $i$ de främmande språkens didaktik (s. 20I-2I7). Stockholm: Stockholm University Press. DOI: https://doi.org/IO.I6993/bbg.j. License: CC-BY 4.o. 
blir den att undersöka utifrån hur elever förstår och använder den skriftliga återkoppling de får på sina skrivna texter eftersom den delen av processen ofta äger rum i tystnad.

För att kunna ge röst till och därmed undersöka elevers förståelse och användning av skriftlig återkoppling utgick min studie utifrån fyra specifika forskningsfrågor. De två första relaterar till hur elever förstår skriftlig återkoppling: Vad säger elever att de förstår av den skriftliga återkoppling de får av läraren? Vad säger eleverna att de har svårt att förstå? De övriga två relaterar till hur elever använder denna: Vilka förändringar säger eleverna att de gör i sina texter som ett resultat av lärarens skriftliga återkoppling? Vilka andra förändringar säger eleverna att de gör i sina texter?

Innan resultaten från studien som presenteras i det är kapitlet redogörs för behöver studien placeras i ett större vetenskapligt sammanhang och då inom de fält som intresserat sig för återkopplingsprocessen, särskilt i relation till skrivande. Därför inleds nästa avsnitt med en bakgrund till svenska elevers skrivande på engelska. Dessutom går jag igenom vilka problem olika forskare har identifierat, ställt frågor kring och försökt besvara när det gäller att skriva och undervisa på ett främmande språk samt när det gäller skriftlig återkoppling.

\section{Vad säger forskningen?}

Trots att elever i svensk grundskola uppnår goda resultat i ämnet engelska både i nationella och internationella mätningar, presterar de inte lika bra i skriftlig produktion som i de receptiva förmågorna; hör- och läsförståelse. En närmare titt på de svenska resultaten för skriftlig produktion i den europeiska studien European Survey on Language Competences, ESLC (European Commission, 20I2) ger dessutom vid handen att den grupp elever vars föräldrar har eftergymnasial utbildning generellt presterar bättre när det gäller skriftlig produktion i engelska. Det skulle kunna tyda på att undervisningen inte ger alla elever optimala möjligheter att utveckla sin skriftliga förmåga. Detta blir problematiskt när skolan har ett kompensatoriskt uppdrag som innebär att den ska kompensera för elevers olika förutsättningar. En förklaring till varför elever inte ges tillräckliga möjligheter att utveckla sin 
skriftliga förmåga är, som den internationella studien visar, att lärare uppger att det är just den förmågan som de ägnar minst tid. Följaktligen blir det relevant att fundera över hur det kommer sig att lärare som undervisar i engelska ägnar minst tid åt skrivundervisning.

En anledning kan vara att det är svårt att undervisa i skrivande i ett främmande språk. De flesta teoretiska modeller som försökt förklara skrivandets process är baserade på skrivande i ett förstaspråk (Flower \& Hayes, I98 I; Bereiter \& Scardamalia, I987) och tar inte hänsyn till den språkliga komponenten dvs. om det rör sig om ett andra- eller ett främmandespråk (Polio, 20I2). Den språkliga komponenten är även en komponent som går förlorad $\mathrm{i}$ ett så kallat processbaserat förhållningssätt, där skrivandets fyra steg stoffsamling, formulerande, bearbetning och utskrift betonas. Även vissa genrebaserade förhållningssätt, som fokuserar på hur olika texttyper är uppbyggda, räcker inte alltid till för att hjälpa lärare att förstå vilka ord och fraser som blir viktiga för elever att använda för att kunna bygga upp till exempel en argumenterande text i engelska som främmande språk.

Hur lärare på bästa sätt kan stötta och utveckla elevers skrivande i ett främmande språk är inte heller enkelt. Den artikel som Truscott (I996) publicerade blev startskottet på en lång debatt om rättningars effekt på elevers andraspråksutveckling. Debatten fortsatte till att omfatta inte bara frågan om lärare ska rätta eller inte, utan även andra frågor som till exempel hur lärare ska rätta, hur mycket lärare ska rätta, hur rättningar påverkar kvaliteten i elevers texter och hur rättningar påverkar elevers motivation till skrivande (Ferris, I999, 2003).

Studier som undersökt skriftlig återkoppling utifrån ett elevperspektiv visar på olika resultat. Elever tycker att det är svårt att förstå lärares rättningar och kommentarer (Sommers, I982; Kronholm-Cederberg, 2009). Ibland tycker eleverna att kommentarerna är motsägelsefulla och förvirrande, särskilt när lärare använder symboler eller förkortningar (Sommers, I982). Det är också svårt för elever att veta vilka kommentarer som är viktigast att ta itu med (Hyland, I998) och trots att de tar itu med all den återkoppling som de får, leder inte det automatiskt till en förbättring av textens kvalitet (Hyland, I998). Andra studier (Lee, 2007; 
Kronholm-Cederberg, 2009) visar att den skriftliga återkoppling som lärare ger främst riktar sig mot form och inte mot innehåll, trots att både form och innehåll bedöms i elevernas texter. Med andra ord kanske inte elever ges möjlighet att utveckla allt det som behövs utvecklas i texten.

Studier har också visat att lärare tycker det är svårt att ge skriftlig återkoppling som inte approprierar, dvs. tar över elevers texter (Sommers, I982; Hyland \& Hyland, 2006). I sin tur vill elever inte alltid följa de ändringar som läraren föreslår eftersom de upplever att texten inte blir deras egen text. Möjligtvis kan svårigheten med appropriering förklaras genom ett synsätt som förstår skrivande och identitet som intimt förknippade (Ivaniç, I998).

Inom bedömningsfältet har man ägnat sig åt att försöka förstå hur bedömning kan användas för att stötta, utveckla och motivera elever. Det engelska ordet feedback (återkoppling) har identifierats som en av de viktigaste strategierna (Wiliam \& Thomson, 2007; Hattie \& Timperely, 2007). Däremot fungerar bara återkopplingsstrategin om mottagaren är beredd att uppmärksamma, ta emot, tolka/förstå och använda den (Council of Europe/ Skolverket, 2009). Mottagarens roll i återkopplingsprocessen har därför lyfts fram (Sadler, I989) och problematiserats (Stobart, 20I2). En lärares återkoppling kan alltså vara informativ, riktad till elevens färdighetsnivå och till en särskild uppgift men behöver inte automatiskt leda till att eleven använder den på att adekvat sätt. Det beror på att elever, under förutsättning att de förstått, kan välja hur de tar emot återkopplingen. Antingen kan de förhandla, acceptera eller använda återkopplingen för att försöka förbättra sitt arbete eller så kan de ändra den eller helt enkelt avfärda den (Stobart, 20I2).

Sammanfattningsvis kan man säga att det finns relevant forskning inom olika fält som knyter ihop och ökar vår förståelse för de frågeställningar som uppmärksammats kring elevers skrivande på ett främmande språk, återkoppling och skrivande samt återkopplingsprocessen. Däremot finns det få studier som undersöker hur elever på grundskolenivå ger uttryck för sin förståelse och användning av lärares skriftliga återkoppling. Det är denna lucka som min studie försöker fylla. I nästa avsnitt presenteras hur studien genomfördes för att undersöka svenska 
elevers förståelse och användning av skriftlig återkoppling i ämnet engelska.

\section{Undersökningens genomförande}

I undersökningen deltog elever från två olika grupper vid två olika skolor, en grupp elever i årskurs 8 och en grupp elever i årskurs 9. Lärarna som undervisade i grupperna hade planerat ett skrivprojekt där eleverna först skulle skriva utkast, sedan få skriftlig återkoppling på sina utkast av läraren och slutligen bearbeta sina texter med hjälp av lärarens återkoppling. Eleverna i årskurs 8 skrev A letter to Barack Obama och eleverna i årskurs 9 skrev en text om temat Movies.

En fallstudiedesign (Yin, 2009) användes för att kunna studera några elever i båda grupperna mer ingående. Materialet som samlades in och användes bestod av elevintervjuer, elevers textutkast och bearbetade texter. Elevintervjuerna genomfördes vid två tillfällen. Den första intervjun genomfördes när eleverna fått skriftlig återkoppling på sina textutkast av läraren och den andra intervjun genomfördes när eleverna bearbetat sina texter. För att få eleverna att just reflektera kring lärarens skriftliga återkoppling och sina bearbetningar användes retrospektiva/reflektiva intervjuer (Mackey \& Gass, 2005).

Lärarnas återkopplingspunkter (på engelska feedback point) identifierades och kategoriserades enligt en feedbacktypologi presenterad av Ellis (2009). Under kategoriseringsarbetet utökades Ellis (2009) feedbacktypologi med nya kategorier, för att täcka in samtliga av lärarnas återkopplingspunkter. Elevernas förståelse av lärarnas återkoppling synliggjordes med hjälp av tematisk analys (Braun \& Clarke, 2006). Tematisk analys är en analysmetod som används för att upptäcka mönster i olika typer av material som till exempel i transkriberade intervjuer. De mönster som urskiljs efter flera genomläsningar av transkriptionerna kan då kategoriseras i olika teman som för den här studien gjorde det möjligt att få syn på olika sätt för eleverna att uttrycka sin förståelse eller brist på förståelse. Elevernas användning av lärarnas återkoppling kategoriserades enligt fyra bearbetningskategorier som presenterats och använts av Hyland (1998): 
I. bearbetningarna följer lärarens rättningar eller förslag

2. återkopplingen påverkar som stimuli och triggar igång ytterligare förändringar utöver de förändringar som den initiala återkopplingen riktat sig mot

3. undvikande av problem som återkopplingen riktat sig mot genom borttagande/radering av problemet utan att ersätta det med något annat

4. bearbetningen kan inte relateras till lärarens skriftliga återkoppling

I nästkommande två avsnitt presenteras undersökningens resultat med utgångspunkt i de fyra forskningsfrågorna. Först presenteras elevernas förståelse av lärarens skriftliga återkoppling och sedan elevernas användning av den återkoppling de fått av läraren.

\section{Vad förstod eleverna av lärarens återkoppling?}

Tillsammans förstod eleverna mer än hälften av lärarens återkopplingspunkter och de uttryckte då på olika sätt att de hade förstått återkopplingen. De flesta eleverna uttryckte sin förståelse genom att använda ett vardagligt språk utan specifik språklig terminologi. Endast en elev använde sig av språklig terminologi och då endast vid ett tillfälle:

(I) jag vet inte ehm ... att jag ska skriva ehm .. 'I get' istället för 'I'm getting' typ ehm för att det är typ så på engelskan att när det är en vana typ så ska man använda 'I get' . . asså typ . inte pågående form (Daniella)

När eleverna uttryckte att de förstått kunde de allra flesta se en anledning till att de fått kommentaren.

(2) jag borde ha utvecklat mer. . jag bor i Stockholm Sverige. hur gammal jag är varför jag skriver . . jag har nästan inte skrivit det (David)

Vissa elever kunde förstå återkopplingspunkten de fått genom att anta ett läsarperspektiv:

(3) jag .. det (styckeindelning) måste jag arbeta på annars kan det bli liksom för jobbigt att läsa texten (Ted) 
Några elever visade sin förståelse genom att helt enkelt tillhandahålla ett korrekt alternativ till det som läraren strukit under.

(4) och sen apartment som är med två p:n (Evelyn)

Vid några tillfällen var det svårt att avgöra om eleverna förstått återkopplingspunkterna eller inte. Särskilt gällde detta för återkopplingspunkter som riktade sig mot att stärka textens sammanhang eller den röda tråden i texten. En elev uttryckte till exempel att hon förstått själva innebörden av lärarens kommentar men att hon inte visste hur hon skulle gå tillväga för att använda den.

(5) Daniella: ah asså jag vet inte riktigt hur jag ska göra där men Forskare: $n \ddot{a}$

Daniella: typ ja visa tydligare asså . vilken koppling dom två ämnena har liksom

Vid några andra tillfällen uttryckte eleverna att de skulle göra ändringar i texten för att läraren uppmanade dem att göra det, men det gick inte att identifiera en förklaring eller en anledning $i$ elevernas utsagor.

(6) $x$ (läraren) har upplyst mig att om vårat radio Sveriges liksom radioförsvar har faktiskt börjat avlyssna svenskar och ge informationen till USA och här framme så skriver jag att vi inte har nånting liknande det $i$ Sverige men då vet jag att vi har det så det kommer jag att ändra på sen (Robert)

Vid några få tillfällen gick det definitivt att fastställa att eleverna inte förstått. Vid dessa tillfällen försökte eleverna att söka efter ledtrådar men lyckades aldrig komma fram till ett korrekt förslag på förändring som i de två exemplen nedan:

(7) Ted: och sen runned här

Forskare: $\mathrm{mm}$ 
Ted: jag vet inte ... det kanske blev fel därför jag vet inte vad jag gjorde fel eller har jag stavat fel? . . hon (läraren) kanske inte saig att det var ett $e$ ?

(8) eh $\mathrm{mm}$. . sexan förstår jag inte riktigt vad hon (läraren) menar med .. om det är ditt eget språk asså menar hon typ såhär om jag använder mitt eget språk typ . . förkortningar och saint eller menar hon slang eller? (Jacob)

Andra gånger uppgav eleverna själva att de inte förstått:

(9) David: kanske det är inte lika formellt

Forskare: okej

David: inte ett så formellt avslut på ett brev

Forskare: $\mathrm{mm}$

David: kanske.. det vet jag inte heller

Svårigheter att förstå återkopplingspunkterna kunde relateras till återkopplingens form. De implicita formerna av återkoppling dvs. när läraren enbart strukit under ett ord, som till exempel runned som i tidigare exempel, eller en mening i texten, försvårade förståelsen för vissa elever. Även användning av språkspecifik terminologi som till exempel meningsstruktur eller uttrycket röd tråd gjorde återkopplingen svår för några av eleverna att förstå.

Vidare visar resultaten av studien att återkopplingen ibland påverkar vissa elever att känna osäkerhet och besvikelse. Särskilt verkar positiv återkoppling som till exempel kommentaren Good! inte ha den önskade effekten. Flera elever tyckte att kommentaren var för generell och ställde sig då undrande till vad läraren tyckte var bra i texten:

(Io) asså den (kommentaren 'Good!' författarens anmärkning) säger inte så mycket förutom att det var bra asså och att det inte var nåt större . . att det inte fanns något större fel direkt (Marie) 
Dessutom uttryckte eleverna också sin besvikelse över att många elever hade fått samma kommentar. Eftersom de själva tyckte att de ansträngt sig med att skriva sin text, förväntade eleverna sig en mer textspecifik kommentar från läraren:

(I I) Ted: asså jag blev lite så här besviken då jag inte fick så mycket ut av den kommentaren . .jag hade hoppats på lite mer . ooch det var väl typ det . . och sen det här är inte första gången jag blir besviken på kommentarerna för typ nån text såhär innan som vi hade gjort tidigare där där så liksom ansträngde jag mig mycket på texten och förväntade mig en såhära bra kommentar som hon (läraren) liksom där hon liksom läst texten och gav mig kommentar om texten . fast det var lite sorgligt att kommentaren jag fick hade typ alla andra i klassen också fätt . . det var typ exakt samma kommentar så jag vet inte riktigt om hon läste texten utan bara skrev kommentar på alla texter samtidigt . . det var lite lite sorgligt kan man säga

Forskare: du blev . . du kände besvikelse för att du hade ansträngt dig?

Ted: mm och så fick jag liksom .. inte kommentaren jag ville ha kan man säga

I detta avsnitt belystes resultaten för de två första av studiens frågor kring elevers förståelse av skriftlig återkoppling. I nästa avsnitt presenteras resultaten av elevernas användning av lärarens återkoppling.

\section{Hur använde eleverna lärarens skriftliga återkoppling?}

Användningen av lärarens återkoppling skiljde sig åt mellan eleverna i de två olika grupperna. I årskurs 8 använde eleverna samtliga av lärarens återkopplingspunkter. De flesta av återkopplingspunkterna ledde till att eleverna gjorde fler och större förändringar i sina texter som ett resultat av lärarens ursprungliga återkoppling. Dessa förändringar bestod oftast i utvecklande av den ursprungliga texten/idén som i exemplet nedan: 
(I2) We don't have $\rightarrow$ I do know that this isn't anything anything like that is exclusive to America. The this in Sweden Swedish federal radio has been donor do we have ing the same thing here in Sweden a prison where and I do find this very upsetting hundreds of too. But what is even more upsetpeople are without a trial. ting is that they are giving the information to America. I do blame Sweden for this the most, but that doesn't make you innocent. You should not accept the information, even if it's offered to you.

En tredjedel följde de rättningar och förslag som läraren angett som belyses i följande exempel:
(13) Almost every month $\rightarrow$ AlmosteverymonthIgetnews I'mgettingnewsabout about some fatal shooting some fatal shooting in in the U.S.A. the U.S.A.

Endast två återkopplingspunkter ledde till att text togs bort. Dessa två återkopplingspunkter gällde att skapa koherens dvs. sammanhang i texten:

(I4) David: jag kände från början att . . nej . . alltså det hänger inte ihop riktigt . .jag kände att det blir bättre om jag går in lite djupare i sjukvården och fattigdomen istället för att lägga energi på dödsstraffet

Forskare: $\mathrm{mm}$

David: så jag tog bort det helt

Forskare: $\mathrm{mm}$

David: och det blev mycket bättre

I årskurs 9 använde eleverna mindre av lärarens återkoppling än eleverna i årskurs 8. Dessutom skiljde sig användningen av lärarens återkoppling från elev till elev. Den elev som använde minst 
återkopplingspunkter gjorde inga förändringar alls i sin text och den som använde flest använde hälften av lärarens punkter. Nästan alla återkopplingspunkter ledde till att eleverna gjorde fler och större förändringar i sina texter än de rättningar och förslag som läraren gett, som i exemplet nedan:

(I5)I totally agree with him $\rightarrow$ And in the quote where for an exampel Horror he says 'movies make you movies make you feel feel' I cannot agree more afraid, Romantic movies with him, because if you're can make you feel watching a Horror movie happy or sad, Adventure movies can get you excited! for an example you might feel scared and a Romantic movie might make you happy or in some cases sad.

Endast några få förändringar följde lärarens rättningar och förslag, som till exempel att rätta stavning av ett ord från diffrent till different eller att byta ut hela ord i en mening: Movies effekts me in different ways till Movies affect me in different ways. I stället gjorde flera elever egna förändringar som inte kunde relateras till lärarens återkopplingspunkter:

(16) Max: ja jag har inte gjort någonting utifrän den (lärarens checklista)

Forskare: nej ingenting?. .

Max: det är bara vad jag själv tycker borde adderas

(I7) eh jag följde inte så mycket efter punkterna . . det var nog mer vad jag själv tyckte och tänkte (Marie)

En återkopplingspunkt ledde till att text togs bort:

Now he can he can sleep like a child or $\rightarrow$ at least be thinks he is.

Efter presentationen av studiens resultat kommer jag nu att i nästa avsnitt skissera några didaktiska implikationer. 


\section{Didaktiska implikationer och reflektioner}

Resultaten som den här studien kommit fram till pekar på att det inte är lätt att ge skriftlig återkoppling som är konstruktiv och som uppfattas som konstruktiv av eleverna. Eftersom resultaten också pekar på att det inte går att veta i förväg vad eleverna kommer att uppfatta som svårt gällande återkopplingen och att det finns flera anledningar till att eleverna väljer att använda återkopplingen eller att inte göra det, går det enbart att skissera några didaktiska implikationer utifrån resultaten av den här studien.

Om vi som lärare väljer att ge skriftlig återkoppling, är det en fördel om våra elever är införstådda med varför vi ger återkoppling, vad vi ger återkoppling på, hur vi ger återkoppling och när vi tänker ge återkoppling.

Först och främst bör lärare fundera över varför skriftlig återkoppling ska användas för att kommunicera något till eleverna om deras texter. Om lärare anser att skriftlig återkoppling är ett värdefullt verktyg är det viktigt att vi 'delar språk' med våra elever oavsett hur vi väljer att ge återkoppling. Det innebär att vi måste förklara de ord vi använder i våra kommentarer, vardagliga eller språkspecifika. Genom att förklara de ord vi använder ger vi också eleverna möjlighet att tillägna sig ett språk att prata om språket, ett så kallat metaspråk. Även symboler kommunicerar något och de måste också förklaras.

Skriftlig återkoppling är ett flexibelt verktyg och kan användas på flera olika sätt med olika syften. Implicita former av återkoppling som understrykning av ord eller fraser, kan utmana elever att fundera över vad som kan tänkas vara fel. Den formen av återkoppling kan användas fokuserad eller ofokuserad och ställer olika krav på elevernas kognitiva förmåga. Den fokuserade återkopplingen kan exempelvis rikta sig mot enbart stavning eller ett visst grammatiskt moment vilket ger eleverna möjlighet att rikta uppmärksamhet mot samma svårighet flera gånger. Den ofokuserade, som kan tänkas vara mer utmanande, riktar sig mot olika slags fel i texten och kan få elever att fundera över vad felet kan handla om.

Resultaten från den här studien visar även att skriftlig återkoppling påverkas av den maktrelation som finns mellan lärare och elev. Det innebär till exempel att eleverna ibland gör förändringar som 
de inte förstår eller att de inte ifrågasätter sådant som de inte tycker stämmer. Detta är viktigt att tänka på eftersom lärare är de som både undervisar elever och bedömer elevers prestationer. En väg att gå skulle kunna vara att använda kamratbedömning som ett komplement till lärares återkoppling, eftersom elever upplever att de lättare kan ifrågasätta och diskutera en kamrats bedömning än en lärares (Zhao, 20Io). Då är det viktigt att komma ihåg att elever behöver tränas i att ge varandra återkoppling (Berggren, 2013).

Återkoppling påverkar också elever på ett känslomässigt plan. Elever kan bli besvikna och därmed omotiverade att bearbeta sina texter om våra kommentarer är för generella. Ett sätt att försöka få elever att känna sig motiverade att bearbeta sina texter och fortsätta att vilja arbeta med sitt skrivande är att göra kommentarerna mer textspecifika. Vi kanske inte behöver värdera elevernas texter i ord som bra utan istället visa nyfikenhet för texten och ställa frågor kring sådant som vi inte förstår eller sådant som är i behov av att utvecklas i texten. Det är också viktigt att fundera över hur vi kan ge återkoppling på textens innehåll utan att för den skull appropriera texten. Ett sätt att göra detta kan vara för läraren att ange att återkopplingspunkten är just ett förslag och att skribenten själv har en valmöjlighet att ändra eller inte.

Avslutningsvis är det viktigt att fundera över om det finns sådant som vi inte kan uppnå med skriftlig återkoppling. Skriftlig återkoppling är ett flexibelt verktyg och har styrkor men kan inte ersätta skrivundervisning. Snarare kan skriftlig återkoppling användas som en del av eller ett komplement till skrivundervisning eftersom alla elever, oavsett om föräldrarna har eftergymnasial utbildning eller inte, måste få möjlighet att lära sig skriva i ämnet engelska. Därför blir lärarens roll viktig, eftersom det är läraren som planerar, genomför och följer upp undervisningen. Lärare i engelska behöver därför ägna mer tid åt att undervisa i skrivande. Särskilt behöver elever hjälp med hur man skapar koherens i en text eller hur man skapar kohesion $\mathrm{i}$ en mening, eftersom eleverna ofta förstår vad som åsyftas men väljer att inte använda återkopplingspunkter riktade just till koherens och kohesion. Därutöver måste skrivundervisningen i engelska erbjuda eleverna många tillfällen att skriva, både kortare och längre texter. Skrivande är en svår förmåga att bemästra och det tar tid att nå resultat, både för lärare och för elever. 


\section{Vad kan en forskande lärare bidra med?}

Att vara forskande lärare har sina fördelar och nackdelar. Fördelen med att vara lärare när man forskar är att de problem och de frågeställningar vi söker svar på tar avstamp i de svårigheter vi lärare upplever i vår vardag. Eftersom klassrummet som miljö fortfarande är en underrepresenterad kontext i forskarvärlden behövs mer forskning kring dessa frågor och problem. En forskande lärare känner väl till miljön och är förtrogen med sitt ämne, vilket kan bidra med ett perspektiv som en forskare som inte är lärare saknar. Nackdelen med att vara forskande lärare är att det kan vara svårt att kliva ur den miljön som man känner väl till och kanske ställa andra typer av frågor som också behöver ställas. Det är inte lätt att utmana våra förgivettaganden och kritiskt granska dessa, men med hjälp av tidigare forskning, teoretiska perspektiv och analytiska verktyg kan vi få syn på det vi tar för givet, formulera frågeställningar, söka och förhoppningsvis hitta svar.

En forskarutbildning ger språklärare möjligheter att fördjupa sina kunskaper inom det språkdidaktiska fältet, men styrkan i en forskarutbildning är att den ger förutsättningar för att arbeta på ett vetenskapligt sätt. Ett vetenskapligt arbetssätt innebär att arbeta systematiskt: upptäcka problem, ställa relevanta frågor för att undersöka problemet, välja en metod som gör det möjligt att samla in data, leta efter verktyg för att kunna analysera den data som samlats in, presentera resultaten på ett överskådligt sätt samt diskutera resultaten. Det är ett arbetssätt som kan översättas till klassrummet och den undervisning som pågår där. I planeringsstadiet kan hänsyn tas till elevers svårigheter och eventuella problem. Den planering vi gjort iscensätts i klassrummet och tillsammans med eleverna får vi lärare bevis på hur den planering vi gjort fungerar. Om vi upptäcker brister i vår planering eller om vi upptäcker att elever har svårigheter blir det med hjälp av ett systematiskt arbetssätt lättare att ställa sig frågan varför och kanske komma fram till några rimliga svar.

Ett systematiskt arbetssätt som utgår från problem och utmaningar i klassrummet och är vetenskapligt grundat i ämnesdidaktisk forskning kan därmed bidra till en undervisning som gynnar elevernas kunskapsutveckling och på lång sikt bidrar till en starkare professionalitet. 


\section{Referenser}

Berggren, J. (2013). Learning from giving feedback: insights from EFL writing classrooms in a Swedish lower secondary school [Licentiatuppsats, Stockholms universitet]. https://www.diva-portal .org/smash/get/diva2:679555/FULLTEXTor.pdf

Bereiter, C., \& Scardamalia, M. (I987). The psychology of written composition. Lawrence Erlbaum Associates. https://doi.org/I0.4324 197802038 I 23 I0

Braun, V., \& Clarke, V. (2006). Using thematic analysis in psychology. Qualitative Research in Psychology, 3, 77-IOI. http://dx.doi.org /IO.II9I/I478088706qpo630a

Ellis, R. (2009). A typology of written corrective feedback types. ELT Journal, 63, 97-I07. https://doi.org/IO.I093/elt/ccno23

Council of Europe/Skolverket (2009). Gemensam europeisk referensram för språk: lärande, undervisning, bedömning. Skolverket. https://www.skolverket.se/publikationer?id=2 I 44

European Commission (2012). First European survey on language competences: final report. https://doi.org/I0.2766/34I60

Ferris, D. ( I 999). The case for grammar correction in L2 writing classes: a response to Truscott. Journal of Second Language Writing, 8, I-I I. https://doi.org/Io.Io I 6/S I 060-3743(99)80 I I0-6

Ferris, D. (2003). Responding to writing. I B. Kroll (Red.), Exploring the dynamics of second language writing, II9-I4O. Cambridge: Cambridge University Press. https://doi.org/IO.IOI7 /CBO978I I395248 IO

Flower, L., \& Hayes, J. R. (I98I). A cognitive process theory of writing. College Composition and Communication, 32, 365-387. https://doi.org/I0.2307/356600

Hattie, J., \& Timperely, H. (2007). The power of feedback. Review of Educational Research, 77, 8I-II2. https://doi.org/I0.3I02 1003465430298487

Hyland, F. (1998). The impact of teacher written feedback on individual writers. Journal of Second Language Writing, 7, 40-53. https:// doi.org/Io.IoI6/SI060-3743(98)900I7-0 
Hyland, K., \& Hyland, F. (2006). Feedback in second language writing: contexts and issues. Cambridge University Press. https:// doi.org/IO.IOI7/978 I I08635547

Ivaniç, R. (1998). Writing and identity: the discoursal construction of identity in academic writing. John Benjamins. https://doi .org/IO.1075/swll.5

Kronholm-Cederberg, A. (2009). Skolans responskultur som skriftpraktik: gymnasisters berättelser om lärarens skriftliga respons på uppsatsen [Doktorsavhandling, Åbo Akademi]. http://bibbild.abo .fi/ediss/2009/KronholmAnnette.pdf

Lee, I. (2007). Understanding teacher's written feedback practices in Hong Kong secondary classrooms. Journal of Second Language Writing, I7, 69-85. https://doi.org/IO.IOI6/j.jslw.2007.I0.00I

Mackey, A., \& Gass, S. M. (2005). Second language research: methodology and design. Lawrence Erlbaum Associates. https://doi .org/I0.4324/978 I 4 I06I 2564

Polio, C. (2OI2). The relevance of second language acquisition theory to the written error correction debate. Journal of Second Language Writing, 2I, 375-3 89. https://doi.org/IO.IOI6/j.jslw.20I 2.09.004

Sadler, D. R. (1989). Formative assessment and the design of instructional systems. Instructional Science, I8, I I9-I44. http://dx.doi .org/IO.1007/BFooII77 I4

Sommers, N. (1982). Responding to student writing. College Composition and Communication, 33, I48-156. https://www .jstor.org/stable/357622

Stobart, G. (2012). Validity in formative assessment. In J. Gardner (Ed.), Assessment and learning (s. 233-242). Sage. http://dx.doi .org/I0.4I35/978 I446250808.nI4

Truscott, J. (1996). The case against grammar correction in L2 writing classes. Language Learning, 46, 327-369. http://doi .org/IO.I I I/j.I467-I770.I996.tboI238.x

Zhao, H. (20I0). Investigating learners' use and understanding of peer and teacher feedback on writing: a comparative study in a Chinese English writing classroom. Assessing Writing, I5, 3-I7. https://doi.org/IO.IOI6/j.asw.20I0.0I.002 
Wiliam, D., \& Thompson, M. (2007). Integrating assessment with instruction: What will it take to make it work? I C.A. Dwyer (Red.), The future of assessment: Shaping teaching and learning (s. 53-82). Lawrence Erlbaum Associates. https://doi.org/I0.4324 /978 I3 I 5086545-3

Yin, R. K. (2009). Case study research: design and methods. Sage. 